\title{
Relationships between noise complaints and socio-economic factors in England
}

\author{
Huan Tonga and Jian Kang ${ }^{\mathrm{a}}$ \\ a Institute for Environmental Design and Engineering, The Bartlett, University College London (UCL), \\ London WC1H ONN, UK
}

\begin{abstract}
Environmental noise has significant effects on urban sustainable development and quality of life. The reporting of noise complaints is carried out in England as a part of environment legislation, providing data for government decision-making. The relationships between noise complaints, a part of urban conflicts, and socio-economic spatial inequalities are significant. This study explores the relationships between noise complaints and socio-economic factors at the city/region level. The noise complaints and socioeconomic datasets from the government's open source data provide input for statistical analysis across all districts and unitary local authorities in England. The results suggest that the impacts of socio-economic factors - including demographic, job-related, property, and deprivation aspects - on noise complaints are generally significant. In addition, cities/regions with a higher proportion of young and single residents tend to have more noise complaints, as do cities/regions with diverse ethnicities and religions. High-density cities/regions with higher unemployment rates are likely to receive more noise complaints. More deprived cities/regions are also prone to an increased noise complaint rate.
\end{abstract}

Keywords: Noise complaint; Demographic factor; Property factor; Job-related factor; Deprivation factor

2020 Sustainable Cities and Society

Received 12 November 2019, Revised 12 October 2020, Accepted 22 October 2020, Available online 4 November 2020. 
Huan Tong, Jian Kang: Sustainable Cities and Society https://doi.org/10.1016/j.scs.2020.102573

\section{Introduction}

Acoustic environmental quality has become a critical factor for improving urban sustainability. Noise has significant negative impacts on health and well-being which is one of the essential goals for developing sustainable cities (Eurostat, 2020; United Nations, 2020; Yuan, Yin, Sun, \& Chen, 2019). The effects of noise involve sleep disorder, loss of hearing, cardiovascular disease, and other physiological disease (Moudon, 2009; Münzel et al., 2018). Apart from that, noise is also a primary contributor to psychological issues, such as stress, anxiety, and depression (Dzhambov \& Dimitrova, 2016; Ouis, 2001). In Europe, environmental noise is estimated to cause more than 10,000 premature deaths per year (Eurostat, 2020). To reduce the impact of noise, a series of policies and actions have been carried out, such as the Environmental Noise Directive in Europe (European Union, 2002), Planning Policy Guidance 24: planning and noise in the UK (Adams et al., 2006), Noise Regulation Law in Japan (Ministry of the Environment, 2000), and Environmental Protection Act in Canada (Government of Canada, 2019). Among these, legislation regarding complaints is an important part. Among environment-related neighbour complaints, the volume of complaints about noise is the greatest. Complaining about noise is a behaviour based on residents' annoyance with noise.

A number of studies have examined the link of noise annoyance to physical characteristics of sound and socio-economic factors. From the physical characteristics of sound perspective, residents are annoyed with a series of noise sources, such as traffic and construction (Brambilla, Casini, Cellai, \& Secchi, 2017; Zambon et al., 2020). In the last decade, wind turbine noise annoyance has received increased research attention as installed global wind power increasing (Janssen, Vos, Eisses, \& Pedersen, 2011; Fredianelli, Carpita, \& Licitra, 2019; Licitra \& Fredianelli, 2013; Pedersen \& Persson Waye, 2004). Apart from noise source, other acoustic indices, such as sound pressure level, Intermittency Ratio and Harmonica index, also have significant impacts on annoyance (Praščević, Mihajlov, Cvetkovic, \& Gajicki, 2017; Wunderli et al., 2016). For instance, the intermittency ratio is explored to describe the urban road traffic noise which is strongly related to annoyance (Brambilla, Confalonieri, \& Benocci, 2019; Brambilla, Benocci, Confalonieri, Roman, \& Zambon, 2020).

Noise annoyance is not only related to physical characteristics of noise but also socioeconomic factors. This point has been examined by a considerable amount of research through small-scale investigations, such as at locations of traffic infrastructure and in parks. For railway, the effects of socio-economic factors on annoyance from railway have been widely discussed (Lim, Kim, Hong, \& Lee, 2006; Licitra, Fredianelli, Petri, \& Vigotti, 2016; Pennig et al., 2012). For instance, Licitra et al. (2016) conducted a long-term survey involving demographic factors of participants when evaluating annoyance due to overall railway noise and vibration in Pisa urban areas. Using a combined questionnaire and noise measurement survey in Great Britain, Fields and Walker (1982) conducted research to examine the impact of about 35 demographic factors on annoyance arising from railway noise. The results show that there are significant relationships between noise annoyance and older dwellings, older respondents, and life-time residents. Apart from railway noise, several studies investigated annoyance from road noise in terms of demographics, residential satisfaction, and other socio-economic factors (Bolte, Tamburlini, \& Kohlhuber, 2009; Miedema \& Vos, 1999; Urban \& Máca, 2013). Other research analysed the impact of personal factors and noise level on annoyance near airports (Babisch et al., 2009; Bröer, 
Huan Tong, Jian Kang: Sustainable Cities and Society https://doi.org/10.1016/j.scs.2020.102573

2007; Licitra, Gagliardi, Fredianelli, \& Simonetti, 2014; Lim, Kim, Hong, \& Lee, 2008; Rylander, Sörensen, \& Kajland, 1972; Vogiatzis \& Remy, 2015). In addition, Fields (1993) investigated the effect of demographic and situational variables on noise annoyance in residential areas. The results showed that, in this case, demographic factors including age, gender, income, socio-economic status, education, homeownership, and type of dwelling have weak relationships with noise annoyance. Yu and Kang (2008) and Rey Gozalo, Barrigón Morillas, Montes González, and Atanasio Moraga (2018) focused on subjective evaluations of the sound level in an urban open space. Aletta, Van Renterghem, and Botteldooren (2018) analysed the effect of demographic factors on sound perception using a case study of a cycling path. A range of correlations have been revealed through such small-scale research.

Although the relationships between socioeconomic factors and noise annoyance have been investigated, the relationships between socioeconomic factors and noise complaints have not been adequately explored, especially on a larger scale. Kang (2006) stated that noise complaints are strongly related to noise annoyance and indicate the areas where residents are highly annoyed with noise, when he analysed noise standards and regulations in Europe. Furthermore, Legewie and Schaeffer (2016) found that the relationships between ethno-racial diversity in a neighbourhood and the number of noise complaints calls was significant. Méndez and Otero (2018) investigated the complex relationships between social inequality and urban conflicts, involving annoying noise, use of parking lots, and other conflicts, in Santiago, Chile. The results showed that the conflicts between neighbours are not only related to individual socio-economic circumstances, it suggested that they form a part of a common framework of intersectional vulnerabilities. Liu, Cheshire, Wang, and Fu (2019) mapped the spatial distribution of each complaint type (including noise-related complaints) across 218 suburbs in Brisbane, Australia, and stated as a limitation of their work that the relationships between neighbour complaints and socioeconomic characteristics had not been examined.

Therefore, the aim of this study is to examine the relationships between various socioeconomic factors and the rate of noise complaints. Based on the literature review and data availability, in this study, socio-economic factors are categorised into four groups: demographic, job-related, property, and deprivation factors. This study uses noise complaints and socio-economic datasets from the government open data source at the district and unitary authority levels across England. While acknowledging that this study focuses on the relationships between noise complaints and socio-economic factors, rather than causality, its results are expected to provide a fundamental understanding of such relationships and their strengths, which is helpful in forming effective noise management strategies.

\section{Method}

\subsection{Geographic samples}

In England, there are different levels of geographical units, such as local authorities, output areas, and postcode areas. However, in terms of noise complaint data, only local authority levels are available, namely county and unitary, and district and unitary, as shown in Fig. 1. To obtain a larger sample size, the district and unitary authority levels were selected for analysis. City/region, including urban, semi-urban, and rural areas, as a strategic and political level of administration and policymaking, was used to refer to district and unitary 
authorities (Bennett, 1985; Leibovitz, 2003). With the aim to analyse at city/region level, this study took cities/regions as the analysis objects, with a total of 325 samples (excluding the Isles of Scilly as noise complaint data is not available).

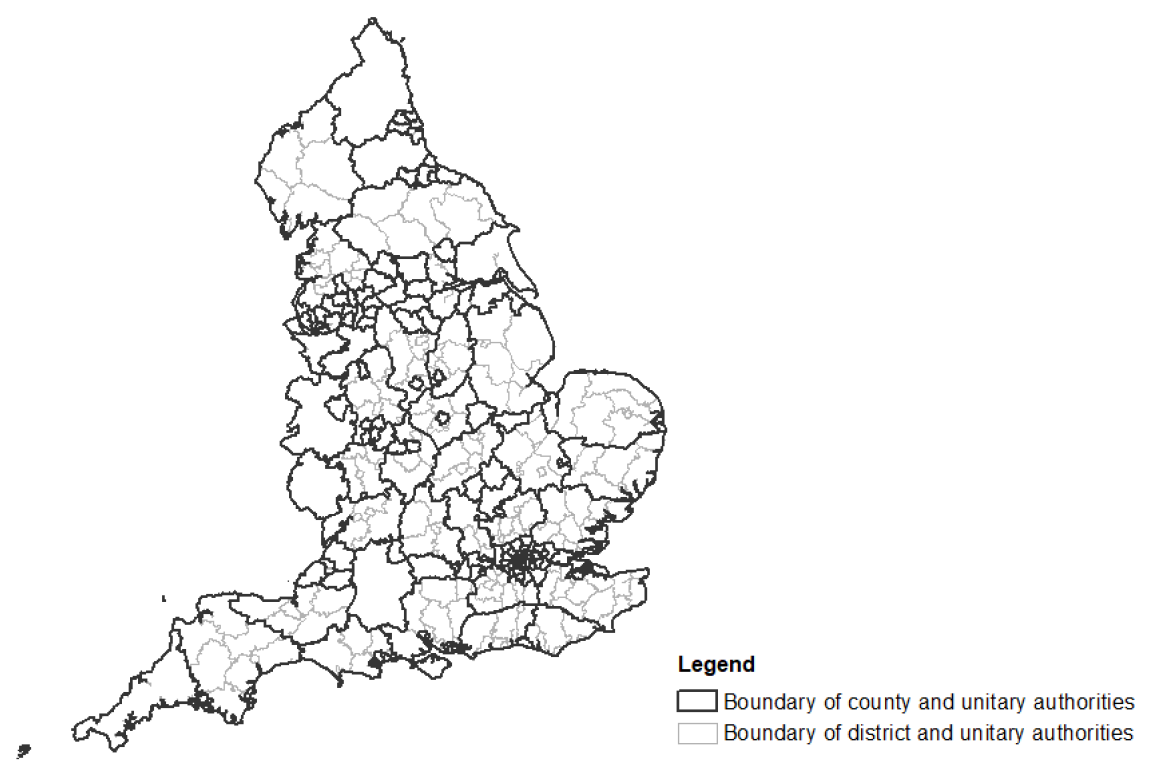

Figure 1. The boundary of local authorities, namely cities/regions in England

\subsection{Noise complaints dataset}

The reporting of noise complaints is carried out in England as a part of environmental legislation in the context of Government policy on sustainable development, providing data for government decision-making (Public Health England, 2018). Reporting a noise complaint is a direct action that residents can take when they are affected by environmental noise, such as road and railway noise, and the complaint is reported to their local authority. Thereafter, the data at city/region level are recorded and released by the local authority. Since the decision to complain is an individual choice, the value of the noise complaint rate for cities/regions cannot be treated as the effect of noise, as not all residents complain. However, this indicator provides a reflection of how many people feel sufficiently affected by noise to cause them to report it (Public Health England, 2018). The noise complaint data can be downloaded from Public Health England, which is an executive agency of the Department of Health and Social Care. Rate and number are the indexes included in the noise complaint dataset.

The rate of noise complaint data was selected to conduct the correlation analysis, with the aim of comparing a large number of cities/regions across various scales. The rates are calculated using the number of complaints, which is collated by the Chartered Institute of Environmental Health, divided by population. The latter value is based on the relevant reference year and mid-year population estimates, multiplied by a factor of 1,000 (Public Health England, 2018). Data on noise complaint rates are available from 2010 to 2015. As the census of 2011 has the most recent and detailed socio-economic dataset, the 2011 rate of noise complaints was selected for the statistical analysis. Overall, there were 399,112 noise complaints reported across all cities/regions in England in 2011. The average number of noise complaints for each city/region in that year was 1,228 , and the 
average rate was 6.7 per thousand people per city/region. These noise complaints have been aggregated into 325 cities/regions, which are samples in this study.

\subsection{Socio-economic factors dataset}

As previous studies argue, there is a wide range of socio-economic factors that can have an impact on sound environment evaluation. On the basis of the literature review and data availability, 76 factors were selected to conduct the correlation analysis. They were categorised into four groups: demographic, job-related, property, and deprivation factors. The detailed factors are shown in Table 1.

Table 1. Indicators of socio-economic factors.

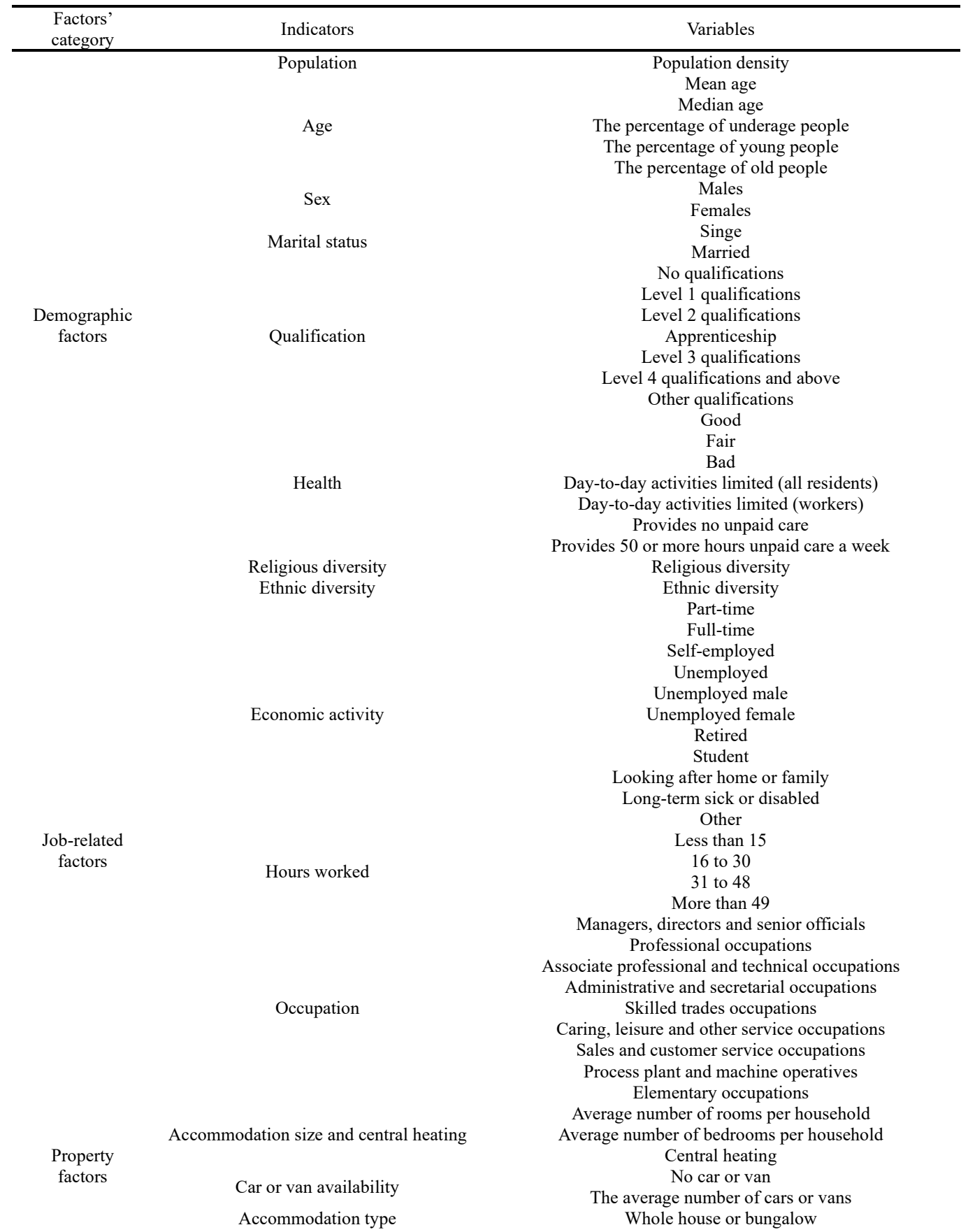




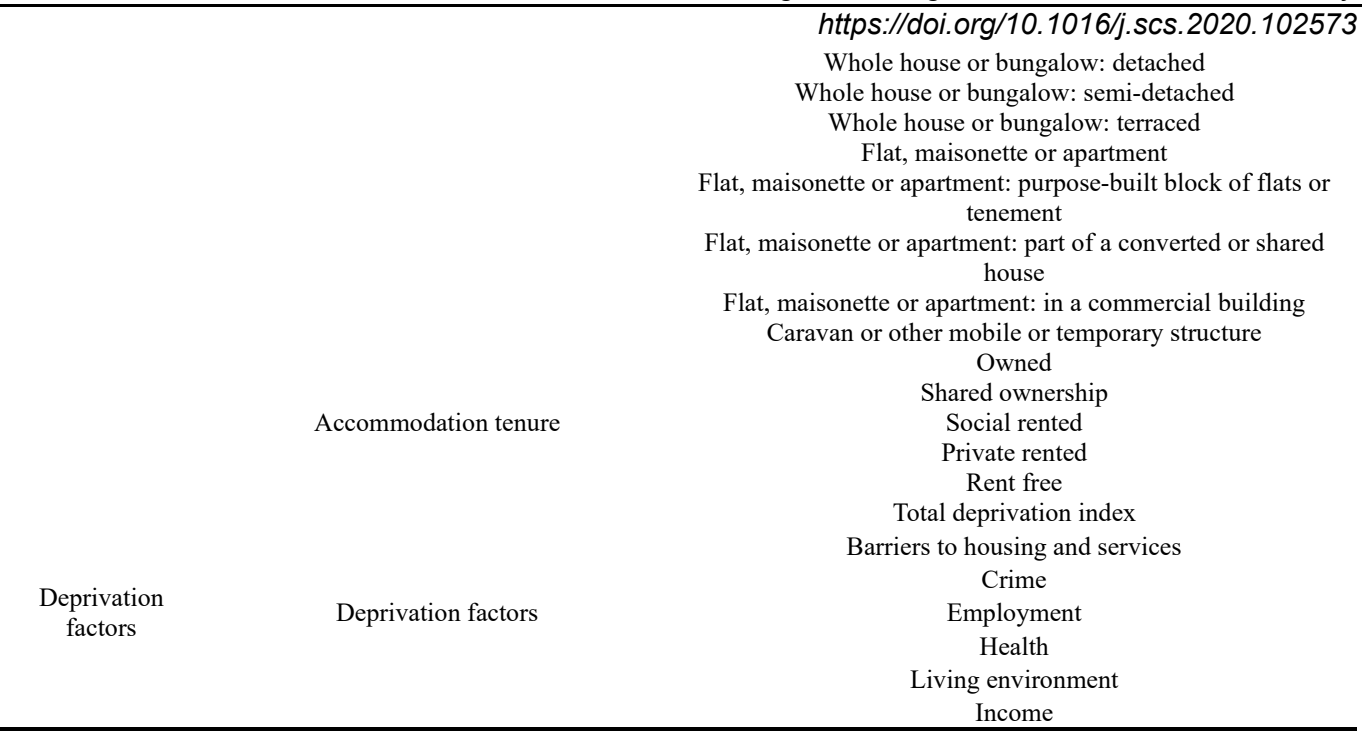

The main open database, used in this study, is Census 2011. The census is a comprehensive investigation, which includes detailed information for each person and Census 2011 is the most recent version published by the Office of National Statistics and taken in March 2011 (Office of National Statistics, 2016). All socio-economic factors were extracted from Census 2011, except the Index of Multiple Deprivation (IMD). IMD, as the official measure of relative deprivation for areas in England, is produced by Department for Communities and Local Government. It is common to describe how relatively deprived a small area is. The IMD ranks every city/region in England from 1 (most deprived area) to 326 (least deprived area). Detailed values are available only for 2010 and 2015 (Department for Communities \& Local Government, 2015). Because there are very strong relationships between IMD 2010 and IMD 2015, the IMD Rank 2010 has been selected for correlation analysis, along with the noise complaints data from 2011. Additionally, a similar result is shown after correlation analysis between IMD 2015 and noise complaints in 2015. The result, using IMD 2010 and noise complaints in 2011, is presented in this paper in order to match other parts of this study.

In terms of ethnicity and religion for cities/regions, the diversity is calculated using Simpson's Diversity Index, which is universally accepted (Gorelick, 2006; Lande, 1996). The formula is:

$$
D=\sum_{i=1}^{S}\left(\frac{N_{i}}{N}\right)^{2}
$$

where $\mathrm{D}$ is Simpson's Diversity Index; $\mathrm{Ni}$ is the population by ethnicity or religion i. Religions comprise Christianity, Buddhism, Hinduism, Judaism, Islam, Sikhism, and Other. Ethnic groups comprise White, Mixed/Multiple, Asian/Asian British, Black/African/Caribbean/Black British, and Other. $\mathrm{N}$ is the total population.

It should be noted that significant correlations are also found between socio-economic factors. For instance, the percentage of old people is related to sex. However, as this study focuses on the impact of individual socio-economic factors on noise complaints, rather than the inter-relationship between the factors. Principle Component Analysis (PCA), as a popular multivariate statistical technique, was provided to get an overall for correlations among variables, and to exact principle component which can partly explain the variance (Abdi \& Williams, 2010). Overall, a number of significant inherent correlations exists among 
Huan Tong, Jian Kang: Sustainable Cities and Society https://doi.org/10.1016/j.scs.2020.102573

the variables. Table for total variance explained, and component matrix were obtained from PCA (Tables A-1 and A-2 in the Appendix in Supplementary materials). With the principle components exacted from PCA, the top three components can explain the $72 \%$ of the variance. From the component matrix, it can be summarised that Component 1 , describing $35.98 \%$ of the data variability, is relatively strongly associated with demographic factors. Component 2, describing $26.90 \%$ of the data variability, can be associated with job-related factors, whereas Component 3 , describing $9.13 \%$ of the data variability, which can be associated with property factors. These results support the categories of socio-economic variables as mentioned above, to some extent. Apart from these three components/categories, deprivation factors, as a synthetic indicator, were presented as an individual category and give an overall assessment of the impact of socio-economic situation on noise complaints.

\subsection{Statistical analysis}

To compare cities/regions across various scales, all other indicators are presented by percentage, such as the percentage of females, excluding deprivation factors, which are shown as rank, mean age, median age, car or van availability, and religious and ethnic diversity. In this study, Shapiro-Wilk test was used to check normality (Ghasemi \& Zahediasl, 2012; Yap \& Sim, 2011). For 76 socio-economic variables, only 8 variables are normally distributed (Table A-3 in the Appendix in Supplementary materials). In particular, the key indicator, noise complaint rate, does not follow a normal distribution. Therefore, Spearman's rho, as a nonparametric test, was applied to measure the relationships between two variables since it does not make any assumption about the distribution of the variables (Hauke \& Kossowski, 2011). The process was conducted using SPSS (Statistical Package for Social Sciences) (Landau \& Everitt, 2003). Spearman's correlation coefficient is interpreted based on the standard published by Quinnipiac University (Akoglu, 2018).

In terms of multivariable analysis, considering sample size, unknown causality, and multicollinearity between variables, a ridge regression model was applied to predict the rate of noise complaints. Ridge regression is a technique for analysing multiple regression data. Compared with regular multiple regression, it is an improved regression model that is useful for dealing with the problem of multicollinearity by adding a degree of bias (Hoerl \& Kennard, 1970; Khalaf \& Shukur, 2005; Marquaridt, 1970). In addition, compared to other modelling methods, this model is analytical with the explanatory contribution of each variable. Hence, it is helpful for the government organisations prioritising resources to dealing with noise pollution in terms of socio-economical aspect. The core idea of this model is to add a degree bias $\lambda$ to the regression estimates for reducing the standard errors. The whole process can be easily realised via the package of the $\mathrm{R}$ language (Friedman, Hastie, \& Tibshirani, 2010; Hastie \& Efron, 2011; Khalaf \& Shukur, 2005; Simon, Friedman, Hastie, \& Tibshirani, 2011). The results are primarily presented in Table 1 and futher analysed in Results and discussion section.

\section{Results and discussion}

\subsection{Demographic factors}

The correlation analysis results of noise complaint rate with population density, age composition, and sex are shown in Table 2. Overall, population density is positively related to rate of noise complaints, with coefficient value of 0.489 . The rate of noise complaints has relatively strong negative correlations with mean and median age, with coefficients of 
about -0.5 . When residents' ages are grouped into three categories, the percentage of underage and young people for cities/regions show positive relationships with noise complaints, with 0.144 and 0.470 as the correlation coefficients, respectively. Old people have a similar correlation coefficient level as young people, but show a negative relationship. The results might be because young people are the primary work force in urban developments. The high percentage of young people implies that the city/region is productive and prone to noise. Another possible explanation is that old people prefer to live in a relatively quiet city/region (Yu \& Kang, 2014).

Table 2. Correlation coefficients of noise complaint rate with population density, resident age and sex.

\begin{tabular}{lccccccc}
\hline $\begin{array}{c}\text { Population } \\
\text { density }\end{array}$ & Mean age & $\begin{array}{c}\text { Median } \\
\text { age }\end{array}$ & $\begin{array}{c}\text { The percentage } \\
\text { of underage } \\
\text { people }\end{array}$ & $\begin{array}{c}\text { The percentage } \\
\text { of young } \\
\text { people }\end{array}$ & $\begin{array}{c}\text { The percentage } \\
\text { of older people }\end{array}$ & $\begin{array}{c}\text { The } \\
\text { percentage of } \\
\text { males }\end{array}$ & $\begin{array}{c}\text { The } \\
\text { percentage of } \\
\text { females }\end{array}$ \\
\hline $0.489^{* *}$ & $-0.497^{* *}$ & $-0.508^{* *}$ & $0.144^{* *}$ & $0.470^{* *}$ & $-0.478^{* *}$ & $0.146^{* *}$ & $-0.146^{* *}$ \\
\hline ** Correlation is significant at the 0.01 level.
\end{tabular}

Apart from age, sex is another basic demographic variable (Table 2). The results indicate that noise complaints have a positive relationship with the proportion of males, indicating that a city/region with a higher proportion of males tends to receive more noise complaints. However, the effect of sex composition of cities/regions on noise complaints has low coefficient values, which reflects the results of previous studies that show that the impact of sex on noise perception is unimportant, to a certain degree (Fields, 1993; Tonin, 1996).

In terms of marital status, a strong positive relationship is found between noise complaints and the proportion of single residents, with a higher coefficient value at 0.529 at a 0.01 significance level, and an adverse relationship with married residents, with a similar coefficient value. Thereby, cities/regions with a higher proportion of couples tend to receive fewer noise reports. It is noteworthy that in terms of noise annoyance, these are controversial results. Miedema and Vos (1999) suggested that residents living in a large family are more annoyed by noise than residents living alone.

Significant correlations are found between residents' highest level of qualification and noise complaints, as shown in Table 3. The percentage of residents with either Level 2 qualifications or an apprenticeship present negative relationships, with coefficient values of -0.221 and -0.308 . The percentage of residents with other qualifications have positive relationships with noise complaints, with coefficient values of 0.508 . Thus, the cities/regions with a higher percentage of residents with a lower education tend to receive less noise nuisance reports.

Table 3. Correlation coefficients between the percentage of residents with various qualification levels and the rate of noise complaints

\begin{tabular}{ccccccc}
\hline $\begin{array}{c}\text { No } \\
\text { qualifications }\end{array}$ & $\begin{array}{c}\text { Level 1 } \\
\text { qualifications }\end{array}$ & $\begin{array}{c}\text { Level 2 } \\
\text { qualifications }\end{array}$ & Apprenticeship & $\begin{array}{c}\text { Level 3 } \\
\text { qualifications }\end{array}$ & $\begin{array}{c}\text { Level 4 } \\
\text { qualifications } \\
\text { and above }\end{array}$ & $\begin{array}{c}\text { Other } \\
\text { qualifications }\end{array}$ \\
\hline-0.003 & -0.012 & $-0.221 * *$ & $-0.308^{* *}$ & -0.101 & 0.050 & $0.508^{* *}$ \\
\hline ** Correlation is significant at the 0.01 level
\end{tabular}

** Correlation is significant at the 0.01 level.

The impact of sound environment on health problems has been intensively investigated (e.g. Dzhambov \& Dimitrova, 2016; Sato, Yano, Björkman, \& Rylander, 1999; 
Schreckenberg, Griefahn, \& Meis, 2010; Welch, Shepherd, Dirks, McBride, \& Marsh, 2013; Wothge, Belke, Möhler, Guski, \& Schreckenberg, 2017). There are three indicators of health: general health, long-term health problems or disability, and provision of unpaid care. The relationships among noise complaints and these indicators are shown in Table 4. General health is a self-assessment of a person's general state of health (University of Durham, 2018a). No significant correlation is seen in terms of the percentage of residents with a good health condition. The percentage of residents with fair health is negatively related to noise complaints, with a coefficient value of -0.117 . Bad health problems show a positive relationship. Noise complaints have a negative relationship with the proportion of residents with a limiting long-term illness, and they have a positive relationship with working residents with a limiting long-term illness. One of the possible explanations for the reverse relationship might be that long-term health problems or disability includes problems that are related to old age. As previously mentioned, the results reinforce the idea that the percentage of old people has a negative correlation with noise. In terms of provision of unpaid care, noise complaints positively relate to the percentage of residents who provide no unpaid care, with a coefficient value of 0.387 . No statistically significant correlation is observed between the percentage of residents who provide 50 or more hours of unpaid care a week and noise complaint rates. It is difficult to explain the relationships between health and noise complaints as health is affected by multiple factors.

Table 4. Correlation coefficients between health factors and the rate of noise complaints.

\begin{tabular}{|c|c|c|c|c|c|c|}
\hline \multicolumn{3}{|c|}{ General Health } & \multicolumn{2}{|c|}{ Long-term health problem or disability } & \multicolumn{2}{|c|}{$\begin{array}{c}\text { Provision of unpaid care per } \\
\text { week }\end{array}$} \\
\hline Good & Fair & $\mathrm{Bad}$ & $\begin{array}{l}\text { Day-to-day activities } \\
\text { limited (all residents) }\end{array}$ & $\begin{array}{c}\text { Day-to-day activities } \\
\text { limited (workers) }\end{array}$ & $\begin{array}{l}\text { No unpaid } \\
\text { care }\end{array}$ & $\begin{array}{c}50 \text { or more } \\
\text { hours }\end{array}$ \\
\hline 0.030 & $-0.117^{*}$ & $0.128 *$ & $-0.144 * *$ & $0.181 * *$ & $0.387 * *$ & -0.074 \\
\hline
\end{tabular}

* Correlation is significant at the 0.05 level.

** Correlation is significant at the 0.01 level.

Both ethnic and religious diversity have strong positive relationships with noise complaints (the correlation coefficients are 0.453 and 0.433 at a 0.01 significance level). In a diverse society, therefore, there could be more conflicts. Residents from different ethnic, cultural, and religious groups are more likely to complain about the noise produced by each other. This finding is consistent with that of Legewie and Schaeffer (2016), who found that residents living between racial enclaves tend to complain more about noise than those who live within clearly defined racial boundaries.

\subsection{Job-related factors}

There are three categories of job-related factors: economic activity, hours worked, and occupation. Economic activity is an indicator of residents' status of employment. The relationships between noise complaints and the percentage of usual residents aged 1674 in England classified by economic activity are presented in Table 5. In terms of being economically active, the percentage of residents with part-time and self-employed jobs has negative relationships with the rate of noise complaints, with coefficients of -0.331 and 0.222 , respectively. Noise complaints do not show correlation with the percentage of residents having full-time jobs. As for the percentage of unemployed residents, the rate of noise complaints is positively related, with coefficient values of 0.441 . A difference is found between unemployed males and females. The coefficient values of unemployed males are 
lower than that of females; therefore, the relationship between noise complaints and unemployed females is stronger than that between noise complaints and males. As for economically inactive residents, a significant negative relationship is found between noise complaints and the percentage of retired residents, with a coefficient of -0.444 . Positive relationships are found between noise complaints and all remaining factors, including the percentage of students and disabled residents. The results indicate that cities/regions with a higher proportion of unemployed residents might be facing more serious noise complaint problems.

Table 5. Correlation coefficients between economic activity status and the rate of noise complaints.

\begin{tabular}{|c|c|c|}
\hline \multirow{6}{*}{ Economically active } & Part-time & $-0.331 * *$ \\
\hline & Full-time & 0.003 \\
\hline & Self- employed & $-0.222 * *$ \\
\hline & Total & $0.441^{* *}$ \\
\hline & Unemployed male & $0.406^{* *}$ \\
\hline & Unemployed female & $0.473^{* *}$ \\
\hline \multirow{5}{*}{ Economically inactive } & Retired & $-0.444 * *$ \\
\hline & Student & $0.365^{* *}$ \\
\hline & Looking after home or family & $0.349 * *$ \\
\hline & Long-term sick or disabled & $0.244^{* *}$ \\
\hline & Other & $0.447 * *$ \\
\hline
\end{tabular}

In terms of the number of hours worked, Table 6 indicates that noise complaints are generally related to this variable. The percentage of residents who work less than 15 hours have a negative relationship with noise complaints, with a coefficient value of -0.183 . A weak positive relationship is found for residents who work from 31 to 48 hours, with a coefficient value of 0.246 . There is no significant correlation between 16-30 hours worked and noise complaints. The percentage of residents who worked more than 49 hours is negatively related to noise complaints, with a low coefficient value of -0.162 .

Table 6. Correlation coefficients between the percentage of residents' hours of work and the rate of noise complaints.

\begin{tabular}{cccc}
\hline Less than 15 & 16 to 30 & 31 to 48 & More than 49 \\
\hline$-0.183^{* *}$ & -0.093 & $0.246^{* *}$ & $-0.162^{* *}$ \\
\hline ** Correlation is significant at the 0.01 level. & &
\end{tabular}

In terms of residents' occupations, the relationships with noise complaints are shown in Table 7, organised top to bottom from professional to entry-level or blue-collar occupations. The proportion of residents with professional or senior occupations have negative relationships with noise complaints, while residents with entry-level or blue-collar occupations have a positive relationship. As the share of managers, directors, senior officials, and skilled trade occupations increases, the rate of noise complaints decreases. In contrast, occupations such as sales, customer service, and elementary occupations 
have negative values in terms of noise complaint rates. The remaining occupations do not show statistically significant correlations. Overall, noise complaints have a negative relationship with the percentage of residents in professional-level occupations. This result is contrary to the findings of Miedema and Vos (1999), who found that residents with higher occupational status are more likely to report noise annoyance, to some extent.

Table 7. Correlation coefficients between the occupation of residents (percentage) and the rate of noise complaints.

\begin{tabular}{cc}
\hline Managers, directors, and senior officials & $-0.289^{* *}$ \\
Professional occupations & 0.010 \\
Associate professional and technical occupations & 0.027 \\
Administrative and secretarial occupations & -0.035 \\
Skilled trades occupations & $-0.293^{* *}$ \\
Caring, leisure, and other service occupations & -0.041 \\
Sales and customer service occupations & $0.229^{* *}$ \\
Process plant and machine operatives & -0.010 \\
Elementary occupations & $0.204^{* *}$ \\
\hline ** Correlation is significant at the 0.01 level
\end{tabular}

** Correlation is significant at the 0.01 level.

\subsection{Property factors}

There were generally significant correlations between property factors and noise complaints. Table 8 shows that noise complaints have a negative relationship with the average number of rooms and bedrooms per household, with coefficient values of -0.528 for rooms and -0.487 for bedrooms. In terms of central heating, the percentage of centrally heated households is negatively related to the rate of noise complaints, with a correlation coefficient value of -0.169 (the household's accommodation is classified as having central heating if it is present in some or in all rooms). In terms of the correlation analysis between car or van availability and noise complaints, the noise complaint rate has a positive relationship with the percentage of households without a car or a van, with a slightly higher coefficient value of 0.482 . In addition, as the average number of car or van per household increases, the noise complaint rate tends to decrease.

Table 8. Correlation coefficients between accommodation condition and the rate of noise complaints.

\begin{tabular}{ccccc}
\hline $\begin{array}{c}\text { Average number of rooms per } \\
\text { household }\end{array}$ & $\begin{array}{c}\text { Average number of bedrooms } \\
\text { per household }\end{array}$ & $\begin{array}{c}\text { Central } \\
\text { heating }\end{array}$ & $\begin{array}{c}\text { No car or } \\
\text { van }\end{array}$ & $\begin{array}{c}\text { The average number of } \\
\text { cars or vans }\end{array}$ \\
\hline$-0.528^{* *}$ & $-0.487^{* *}$ & $-0.169^{* *}$ & $0.482^{* *}$ & $-0.481^{* *}$ \\
\hline$* *$ Correlation is significant at the 0.01 level. & & &
\end{tabular}

Fields (1993), Tonin (1996), and Yano, Sato, Björkman, and Rylander (2002) have found evidence that the type and tenure of accommodation may have impacts on noise annoyance. The correlation coefficients between accommodation type and tenure and noise complaints are shown in Table 9. In terms of accommodation type, negative relationships are found between the proportion of residents living in a whole house or bungalow and noise complaints, with a coefficient value of -0.433 . Detached and semi- 
detached dwellings also have negative relationships with noise complaints, with lower coefficient values of -0.482 and -0.173 , respectively. Noise complaints, however, are positively related to the proportion of residents living in terraced houses. Similar relationships appear for flats: noise complaints are generally positively related to the proportion of residents living in a flat, with coefficient values of $0.455,0.336$, and 0.217 , for purpose-built blocks of flats or tenements, for part of a converted or shared house, and for commercial buildings, respectively. To some extent, terraced houses are more similar to flats in spatial patterns as the rooms are contiguous, although they are categorised under whole house or bungalow. Therefore, they show similar relationships with noise. As for the last variable, caravan or other mobile or temporary structure, it is positively related to noise complaints. The results show that cities/regions with more residents living in flats have an increasing rate of complaint activity. This result may be because a higher percentage of residents living in flats indicates that the city/region is a high-density area. Because of high traffic volumes in high-density areas, there is likely to be a more extreme noise environment in locations with a high percentage of residents living in flats. Another possible reason is that residents living in flats are more influenced by noise nuisance caused by residents living in the same block or building.

Table 9. Correlation coefficients between accommodation type and tenure, and the rate of noise complaints.

\begin{tabular}{lcc}
\hline & Whole house or bungalow & $-0.433^{* *}$ \\
Detached & $-0.482^{* *}$ \\
Accommodation type & Semi-detached & $-0.173^{* *}$ \\
& Terraced & $0.309^{* *}$ \\
& Flat, maisonette, or apartment & $0.442^{* *}$ \\
& Purpose-built block of flats or tenement & $0.455^{* *}$ \\
Part of a converted or shared house & $0.336^{* *}$ \\
Tenure & In commercial building & $0.217^{* *}$ \\
\hline Caravan or other mobile or temporary structure & Owned & $-0.320^{* *}$ \\
& Shared ownership & $-0.509^{* *}$ \\
& Socially rented & $0.145^{* *}$ \\
& Privately rented & $0.368^{* *}$
\end{tabular}

The results of tenure are shown in Table 9. It can be clearly seen that there is a significant and strong inverse relationship between noise complaints and the percentage of a household that owns the accommodation it occupies, with a coefficient value of -0.509 . However, noise complaints appear to be positively related to the percentage of households who share ownership with others, with a lower coefficient value of 0.145 . Households living in rented accommodation are classified by the type of landlord who owns or manages the accommodation. The rate of noise complaints has positive relationships with the percentage of households that rents from social and private properties, with higher 
coefficient values of 0.368 and 0.452 , respectively. 'Socially rented' means that the accommodation is rented from the council and other landlords, and this type is cheaper than privately rented property. A higher proportion of socially rented dwellings implies that the residents' income might be lower. The results show that cities/regions with a higher proportion of households living in socially rented dwellings receive more noise complaints. The result corresponds to Xie and Kang's (2010) study, which reports that people's median income is generally higher in noisier boroughs.

In relatively quiet cities/regions, there are fewer tenants. A possible explanation is that residents are more likely to invest in dwellings in a relatively quiet area. Owners pay more attention to the surroundings of the dwelling than those who rent, since tenants have a lower transaction cost of relocation compared with homeowners. This means that if the dwelling is owned by the resident, it is more likely to be located in an area with a better environment (DiPasquale \& Glaeser, 1999). Another possible reason is that areas with more renters may imply greater intentions to leave; therefore, they are likely to have a negative relationship with their neighbours. However, the finding is contrary to the study of Nieuwenhuis, Völker, and Flap (2013), which suggests, to some extent, that there is no significant difference between renters and owners in terms of relationships with neighbours.

\subsection{Deprivation factors}

In terms of deprivation factors, Table 10 shows the correlation analysis results between noise complaints and the IMD Rank, including total deprivation, income deprivation, employment deprivation, health deprivation, barriers to housing and services deprivation, crime deprivation, and living environment deprivation. The first-ranked cities/regions represent the most deprived cities/regions, namely disadvantaged areas. The results show a negative relationship between total deprivation and noise complaints, with a coefficient value of -0.378 , indicating that more deprived cities/regions tend to have more noise complaints. In terms of barriers to housing and services, crime, living environment, and income deprivation all have negative relationships with noise complaints, with similar coefficient values, compared to total deprivation. Employment and health are also negatively related to noise complaints, but with lower coefficient values.

Table 10. Correlation coefficients between deprivation factors and the rate of noise complaints.

\begin{tabular}{ccccccc}
\hline $\begin{array}{c}\text { Total deprivation } \\
\text { index }\end{array}$ & $\begin{array}{c}\text { Barriers to housing and } \\
\text { services }\end{array}$ & Crime & Employment & Health & $\begin{array}{c}\text { Living } \\
\text { environment }\end{array}$ & Income \\
$-0.378^{* *}$ & $-0.143^{* *}$ & $-0.543^{* *}$ & $-0.272^{* *}$ & $-0.278^{* *}$ & $-0.251^{* *}$ & $-0.396^{* *}$ \\
\hline
\end{tabular}

** Correlation is significant at the 0.01 level.

The results suggest that areas with higher rates of people who die prematurely or whose quality of life is impaired by poor health or who are disabled are likely to report more noise issues, and it might be more difficult for those residents to access local services such as shops, GPs, schools, and post offices in such areas. The findings are consistent with Xie and Kang (2009), who found a negative relationship between deprivation indexes and noise level at neighbourhood level.

\subsection{Ridge regression model for the noise complaint rate prediction}

After figuring out relationships between the rate of noise complaints and 76 individual 
Huan Tong, Jian Kang: Sustainable Cities and Society

https://doi.org/10.1016/j.scs.2020.102573

socio-economic factors, a multivariate model was developed to predict the noise complaint rate. Based on the ridge regression model, the mean square error of this model is 0.369 , which, in this study, is better than most other models such as hierarchical regression, path analysis and lasso regression. The prediction equation based on the ridge regression model is as follows:

$$
\text { The rate of noise complaints }=\sum_{i=1}^{n} R C_{i} * A_{i}+b
$$

where $\mathrm{Ai}$ represents the indicators of socio-economic factors and the $\mathrm{RCi}$ indicates the corresponding regression coefficient value of each variable as shown in Table A-4 (in the Appendix in Supplementary materials). b indicates the regression intercept. In this study, the value of $b$ is 10.22. In terms of the model application, for instance, Bristol is a major city in South West England with 39.10 persons per hectare and population size of 428,074. The noise complaint rate of Bristol is 10.18 per thousand persons, with the prediction value of 9.78. This model will not only provide an effective way for the noise complaint rate prediction at cities/regions scale, but can help the government organisations to prioritise resources for dealing with noise pollution from the socio-economical aspect.

\section{Conclusions}

The noise complaints and socio-economic datasets from the government's open source data provide input for statistical analysis across all districts and unitary local authorities in England. This study used multi-sourced open data rather than questionnaire or interview which are widely applied in sound environment research. The usage of such spatial data enables us to analyse urban issues at a larger scale, longer term and broader spatial coverage. Based on statistical analysis, this study examines the relationships between noise complaints and socio-economic factors, including demographic, job-related, property, and deprivation factors.

In general, various aspects of socio-economic factors have effects on noise complaints. Individually, first, from the perspective of demographic factors, complainants are likely to live in an area with diverse religions and ethnicities. From the results, it can be inferred that cities/regions with a higher proportion of single individuals are prone to receive more noise complaints. Moreover, if the unemployment rate of the cities/regions is higher, residents tend to report more noise issues. The results show unemployment rate of females has a stronger relationship with noise complaints than that of males. Furthermore, as for property factors, if there are more flats or rented houses in an area, noise problems become considerably significant. Finally, more deprived cities/regions tend to have more noise complaints in terms of each aspect in the deprivation index: housing and services, crime, employment, health, environment, and income.

This study has revealed the strengths of the relationships between each socio-economic factor and noise complaints, and it can contribute a multivariate model to predict the noise complaint rate. From these results, profiles of cities/regions can be drawn up from the perspective of noise complaints and socio-economic factors. Furthermore, these results can help government organisations to build a liveable and sustainable city by prioritising resources in terms of ambient noise, both geographically and socio-economically. For instance, if a city/region has a higher unemployment rate, it tends to have a higher noise complaint rate. Therefore, more resources could be allocated in such cities/regions. 
This study suggests a number of possibilities for future research. First, this study primarily considers noise complaints; research on other types of complaints is needed, such as wasting water, air pollution, and public health. Second, although the relationships between socio-economic factors and noise complaint rates have been identified, the causality of these relationships remains undiscussed. With more data on complainants' characteristics, such as sex, occupation, qualification, and other socio-economic factors, the causality and motivation for complaints could be better understood. Third, the present study has considered only the district and local authority levels. To develop a comprehensive understanding of noise complaints, additional studies based on other scales are required. For instance, location information of individual complaints could be used to examine the impact of urban morphology on noise complaint rates. Fourth, this study has primarily focused on noise complaints, which is a behaviour, instead of noise level and noise exposure. A noise map could facilitate this study. However, they are mostly only available in cities with more than 100,000 inhabitants (European Union, 2002). If the dataset is systematically available, future studies could focus on the links between noise complaints and other aspects of noise research.

\section{Declaration of Competing Interest}

The authors declare that they have no known competing financial interests or personal relationships that could have appeared to influence the work reported in this paper.

\section{Acknowledgments}

The support from the European Research Council (ERC) Advanced Grant (no. 740696) on "Soundscape Indices" (SSID) and the UKRI (EP/X123456/1) are acknowledged.

\section{References}

Abdi, H., \& Williams, L. J. (2010). Principal component analysis. Wiley Interdisciplinary Reviews Computational Statistics, 2(4), 433-459.

Adams, M., Cox, T., Moore, G., Croxford, B., Refaee, M., \& Sharples, S. (2006). Sustainable soundscapes: Noise policy and the urban experience. Urban Studies, 43 (13), 2385-2398.

Akoglu, H. (2018). User's guide to correlation coefficients. Turkish Journal of Emergency Medicine, 18(3), 91-93.

Aletta, F., Van Renterghem, T., \& Botteldooren, D. (2018). Influence of personal factors on sound perception and overall experience in urban green areas. A case study of a cycling path highly exposed to road traffic noise. International Journal of Environmental Research and Public Health, 15(6), 1118.

Babisch, W., Houthuijs, D., Pershagen, G., Cadum, E., Katsouyanni, K., Velonakis, M., ... Järup, L. (2009). Annoyance due to aircraft noise has increased over the years: Results of the HYENA study. Environment International, 35(8), 1169-1176.

Bennett, R. (1985). Central City - City region fiscal disparities in Austria: Estimates for 1979. Urban Studies, 22(1), 69-81.

Bolte, G., Tamburlini, G., \& Kohlhuber, M. (2009). Environmental inequalities among children in Europe: Evaluation of scientific evidence and policy implications. European 
Journal of Public Health, 20(1), 14-20.

Brambilla, G., Benocci, R., Confalonieri, C., Roman, H. E., \& Zambon, G. (2020). Classification of urban road traffic noise based on sound energy and eventfulness indicators. Applied Sciences, 10(7), 2451.

Brambilla, G., Casini, D., Cellai, G., \& Secchi, S. (2017). Characterization of short duration noise events for the evaluation of annoyance in schools exposed to traffic noise. In Proceedings of the 24th international conference on sound and vibrations (pp. 23-27).

Brambilla, G., Confalonieri, C., \& Benocci, R. (2019). Application of the intermittency ratio metric for the classification of urban sites based on road traffic noise events. Sensors, 19(23), 5136.

Bröor, C. (2007). Aircraft noise and risk politics. Health, Risk \& Society, 9(1), 37-52.

Department for Communities and Local Government. (2015). The English index of multiple deprivation (IMD) 2015 - Guidance. London: Department for Communities and Local Government.

DiPasquale, D., \& Glaeser, E. (1999). Incentives and social capital: Are homeowners better citizens? Journal of Urban Economics, 45(2), 354-384.

Dzhambov, A., \& Dimitrova, D. (2016). Occupational noise and ischemic heart disease: A systematic review. Noise \& Health, 18(83), 167.

European Union. (2002). Directive 2002/49/EC relating to the assessment and management of environmental noise. Official Journal of the European Communities, $(L, 189 / 12)$.

Eurostat. (2020). Sustainable development in the European Union - Monitoring report on progress towards the SDGs in an EU context. Luxembourg: 4th. Publications Office of the European Union. https://doi.org/10.2785/555257, 2020.

Fields, J. M. (1993). Effect of personal and situational variables on noise annoyance in residential areas. Journal of the Acoustical Society of America, 93(5), 2753-2763.

Fields, J. M., \& Walker, J. G. (1982). The response to railway noise in residential areas in Great Britain. Journal of Sound and Vibration, 85(2), 177-255.

Fredianelli, L., Carpita, S., \& Licitra, G. (2019). A procedure for deriving wind turbine noise limits by taking into account annoyance. The Science of the Total Environment, 648, 728736.

Friedman, J., Hastie, T., \& Tibshirani, R. (2010). Regularization paths for generalized linear models via coordinate descent. Journal of Statistical Software, 33(1), 1-22.

Ghasemi, A., \& Zahediasl, S. (2012). Normality tests for statistical analysis: A guide for non-statisticians. International Journal of Endocrinology and Metabolism, 10(2), 486.

Gorelick, R. (2006). Combining richness and abundance into a single diversity index using matrix analogues of Shannon's and Simpson's indices. Ecography, 29(4), 525-530.

Government of Canada. (2019). Canadian environmental protection act. Available at htt ps://www.canada.ca/en/environment-climate-change/services/canadian-environ mental- 
protection-act-registry/guidelines-objectives-codes-practice/guidelines-obj ectives.html.

Hastie, T., \& Efron, B. (2011). LARS: Least angle regression, lasso and forward stagewise. $\mathrm{R}$ package version $0.9-8$.

Hauke, J., \& Kossowski, T. (2011). Comparison of values of Pearson's and Spearman's correlation coefficients on the same sets of data. Quaestiones Geographicae, 30(2), 8793.

Hoerl, A. E., \& Kennard, R. W. (1970). Ridge regression: Biased estimation for nonorthogonal problems. Technometrics, 12(1), 55-67.

Janssen, S. A., Vos, H., Eisses, A. R., \& Pedersen, E. (2011). A comparison between exposure-response relationships for wind turbine annoyance and annoyance due to other noise sources. The Journal of the Acoustical Society of America, 130(6), 3746-3753.

Kang, J. (2006). Urban sound environment. Boca Raton, FL: CRC Press.

Khalaf, G., \& Shukur, G. (2005). Choosing ridge parameter for regression problems. Communications in Statistics - Theory and Methods, 34(5), 1177-1182.

Landau, S., \& Everitt, B. S. (2003). A handbook of statistical analyses using SPSS. Chapman and Hall/CRC.

Lande, R. (1996). Statistics and partitioning of species diversity, and similarity among multiple communities. Oikos, 76(1), 5.

Legewie, J., \& Schaeffer, M. (2016). Contested boundaries: Explaining where ethnoracial diversity provokes neighbourhood conflict. American Journal of Sociology, 122(1), 125161.

Leibovitz, J. (2003). Institutional barriers to associative city-region governance: The politics of institution-building and economic governance in 'Canada's Technology Triangle'. Urban Studies, 40(13), 2613-2642.

Licitra, G., \& Fredianelli, L. (2013). Which limits for wind turbine noise? A comparison with other types of sources using a common metric. In Proceedings of the 5th international conference on wind turbine noise (pp. 28-30).

Licitra, G., Fredianelli, L., Petri, D., \& Vigotti, M. A. (2016). Annoyance evaluation due to overall railway noise and vibration in Pisa urban areas. The Science of the Total Environment, 568, 1315-1325.

Licitra, G., Gagliardi, P., Fredianelli, L., \& Simonetti, D. (2014). Noise mitigation action plan of Pisa civil and military airport and its effects on people exposure. Applied Acoustics, 84, 25-36.

Lim, C., Kim, J., Hong, J., \& Lee, S. (2006). The relationship between railway noise and community annoyance in Korea. The Journal of the Acoustical Society of America, 120 (4), 2037-2042.

Lim, C., Kim, J., Hong, J., \& Lee, S. (2008). Effect of background noise levels on community annoyance from aircraft noise. The Journal of the Acoustical Society of America, 123(2), 766-771. 
Liu, Y., Cheshire, L., Wang, S., \& Fu, X. (2019). A socio-spatial analysis of neighbour complaints using large-scale administrative data: The case in Brisbane, Australia. Cities, 90, 168-180.

Marquaridt, D. W. (1970). Generalized inverses, ridge regression, biased linear estimation, and nonlinear estimation. Technometrics, 12(3), 591-612.

M'endez, M., \& Otero, G. (2018). Neighbourhood conflicts, socio-spatial inequalities, and residential stigmatisation in Santiago, Chile. Cities, 74, 75-82.

Miedema, H. M., \& Vos, H. (1999). Demographic and attitudinal factors that modify annoyance from transportation noise. The Journal of the Acoustical Society of America, 105(6), 3336-3344.

Ministry of the Environment. (2000). Noise regulation law. Available at: https://www. env.go.jp/en/laws/air/noise/index.html.

Moudon, A. V. (2009). Real noise from the urban environment: How ambient community noise affects health and what can be done about it. American Journal of Preventive Medicine, 37(2), 167-171.

Münzel, T., Sørensen, M., Schmidt, F., Schmidt, E., Steven, S., Kröller-Sch"on, S., \& Daiber, A. (2018). The adverse effects of environmental noise exposure on oxidative stress and cardiovascular risk. Antioxidants \& Redox Signaling, 28(9), 873-908.

Nieuwenhuis, J., V"olker, B., \& Flap, H. (2013). A bad neighbour is as great a plague as a good one is a great blessing: On negative relationships between neighbours. Urban Studies, 50(14), 2904-2921.

Office of National Statistics. (2016). 2011 census data - Office for national statistics. Available at: https://www.ons.gov.uk/census/2011census/2011censusdata.

Ouis, D. (2001). Annoyance from road traffic noise: A review. Journal of Environmental Psychology, 21(1), 101-120.

Pedersen, E., \& Persson Waye, K. (2004). Perception and annoyance due to wind turbine noise - a dose - response relationship. The Journal of the Acoustical Society of America, 116(6), 3460-3470.

Pennig, S., Quehl, J., Mueller, U., Rolny, V., Maass, H., Basner, M., \& Elmenhorst, E. M. (2012). Annoyance and self-reported sleep disturbance due to night-time railway noise examined in the field. The Journal of the Acoustical Society of America, 132(5), 3109-3117.

Prǎšcevi'c, M., Mihajlov, D., Cvetkovic, D., \& Gajicki, A. (2017). Long-term noise measurements and harmonica index as a way of raising public awareness about traffic noise in the city of Nis. Facta Universitatis, Series: Working and Living Environmental Protection, 041-051.

Public Health England. (2018). Public health profiles. Available at: https://fingertips.phe. org.uk/search/noise\#page/6/gid/1/pat/6/par/E12000004/ati/102/are/E10000018.

Rey Gozalo, G., Barrig'on Morillas, J., Montes Gonz'alez, D., \& Atanasio Moraga, P. (2018). Relationships among satisfaction, noise perception, and use of urban green spaces. The Science of the Total Environment, 624, 438-450. 
Rylander, R., S"orensen, S., \& Kajland, A. (1972). Annoyance reactions from aircraft noise exposure. Journal of Sound and Vibration, 24(4), 419-444.

Sato, T., Yano, T., Bjöorkman, M., \& Rylander, R. (1999). Comparison of community responses to road traffic noise among residents of different types of housing. In J. Cuschieri (Ed.), Proceedings of the 1999 international congress on noise control engineering (pp. 321-1326).

Schreckenberg, D., Griefahn, B., \& Meis, M. (2010). The associations between noise sensitivity, reported physical and mental health, perceived environmental quality, and noise annoyance. Noise \& Health, 12(46), 7-16.

Simon, N., Friedman, J., Hastie, T., \& Tibshirani, R. (2011). Regularization paths for cox's proportional hazards model via coordinate descent. Journal of Statistical Software, 39(5), $1-13$.

Tonin, R. (1996). A method of strategic traffic noise impact analysis. Inter-Noise (pp. 23952400). Liverpool, UK.

United Nations. (2020). The sustainable development goals report 2020. Available at: https ://unstats.un.org/sdgs/report/2020/.

University of Durham. (2018). KS301EW (Health and provision of unpaid care). Available at: Nomis - Official Labour Market Statistics https://www.nomisweb.co.uk/census/ 2011/ks301ew.

Urban, J., \& M'aca, V. (2013). Linking traffic noise, noise annoyance and life satisfaction: A case study. International Journal of Environmental Research and Public Health, 10(5), 1895-1915.

Vogiatzis, K., \& Remy, N. (2015). Assessment of the environmental noise due to aircraft operation at the CORFU international airport according to the 2002/49/EC directive and the new Greek national legislation. Proceedings of the Euronoise, 348-352.

Welch, D., Shepherd, D., Dirks, K. N., McBride, D., \& Marsh, S. (2013). Road traffic noise and health-related quality of life: A cross-sectional study. Noise \& Health, 15(65), 224-230.

Wothge, J., Belke, C., M"ohler, U., Guski, R., \& Schreckenberg, D. (2017). The combined effects of aircraft and road traffic noise and aircraft and railway noise on noise annoyance: An analysis in the context of the Joint Research Initiative NORAH. International Journal of Environmental Research and Public Health, 14(8), 871.

Wunderli, J. M., Pieren, R., Habermacher, M., Vienneau, D., Cajochen, C., Probst- Hensch, N., R"öosli, M., \& Brink, M. (2016). Intermittency ratio: A metric reflecting short-term temporal variations of transportation noise exposure. Journal of Exposure Science \& Environmental Epidemiology, 26(6), 575-585.

Xie, H., \& Kang, J. (2009). Relationships between environmental noise and socialeconomic factors: Case studies based on NHS hospitals in Greater London. Renewe Energ, 34(9), 2044-2053.

Xie, H., \& Kang, J. (2010). On the relationships between environmental noise and socioeconomic factors in Greater London. Acta Acustica United With Acustica, 96(3), 472-481. 
Yano, T., Sato, T., Bjöorkman, M., \& Rylander, R. (2002). Comparison of community response to road traffic noise in Japan and Sweden-Part II: Path analysis. Journal of Sound and Vibration, 250(1), 169-174.

Yap, B. W., \& Sim, C. H. (2011). Comparisons of various types of normality tests. Journal of Statistical Computation and Simulation, 81(12), 2141-2155.

Yu, C. J., \& Kang, J. (2014). Soundscape in the sustainable living environment: A crosscultural comparison between the UK and Taiwan. The Science of the Total Environment, 482, 501-509.

Yu, L., \& Kang, J. (2008). Effects of social, demographical and behavioural factors on the sound level evaluation in urban open spaces. The Journal of the Acoustical Society of America, 123(2), 772-783.

Yuan, M., Yin, C., Sun, Y., \& Chen, W. (2019). Examining the associations between urban built environment and noise pollution in high-density high-rise urban areas: A case study in Wuhan, China. Sustainable Cities and Society, 50, Article 101678.

Zambon, G., Muchetti, S. S., Salvi, D., Angelini, F., Brambilla, G., \& Benocci, R. (2020). Analysis of noise annoyance complaints in the city of Milan, Italy. Journal of Physics Conference Series, 1603(1), Article 012029. IOP Publishing. 